\author{
TAL SAGIE \\ Bedwetting Clinics \\ Israel
}

\title{
THE GAP BETWEEN \\ SOCIAL FUNCTIONING TO EMOTIONAL FUNCTIONING AMONG YOUNG ADOLESCENTS WITH NOCTURNAL ENURESIS
}

\begin{abstract}
Sagie Tal, The Gap Between Social Functioning to Emotional Functioning Among Young Adolescents with Nocturnal Enuresis [Różnice pomiędzy zachowaniami społecznymi a emocjonalnymi u dzieci z moczeniem nocnym]. Studia Edukacyjne nr 32, 2014, Poznań 2014, pp. 357-373. Adam Mickiewicz University Press. ISBN 978-83-232-2837-0. ISSN 1233-6688

For many decades, Nocturnal Enuresis (NE, Bedwetting) has been investigated mainly among children. There are many studies that have checked the impact of NE on the social and emotional functioning of children, but less focus was given on young adolescence and adolescence.

The first part of this article will shed more light on NE in general. The second part will discuss the social and emotional functioning of enuretics. The third part will focus on young adolescents with NE. The last part of this article will suggest a new gap model, between the social to the emotional state of the enuretic young adolescent. This gap will be explained in perspective of the SelfDiscrepancy theory (SDT).
\end{abstract}

Key words: pedagogy, psychology, therapy, nocturnal enuresis, emotional functioning, social functioning, adolescents, developmental delay, self-discrepancy theory

\section{Introduction}

Nocturnal Enuresis (Bedwetting) is one of the most frequent and one of the most annoying disorders of childhood. Approximately $5-10 \%$ of seven year-olds frequently suffer from bedwetting, and the problem may carry on into adolescence.

In this article the author will define Nocturnal Enuresis and discuss the relationship between Social and Emotional functioning to Nocturnal Enuresis. 
In the last part of this article the author will try and explain his assumption regarding the gap that exist between the enuretic youngster's actual self to his ideal self; during his childhood, the enuretic child might not consider his bedwetting as an issue. However, as age progress, there is a possibility that the enuretic young adolescence would relate to his functioning as abnormal. The youngster could understand that he is different compared to his peer group and this insight could lead to a major gap between the child's current social status that could be good to his personal secret. In other words, there could be a gap between the child's actual self (real self) to the ideal self. This gap might lead to emotional issues and later on affect the social status. In order to explain this assumption, the author chooses to use the "Self discrepancy theory."1

\section{Enuresis: a common issue among children and adolescents}

Nocturnal Enuresis (NE, Bedwetting) is a common and upsetting experience for children and their parents. ${ }^{2}$ Even though enuresis is considered to be one of the most common disorders among children, unfortunately many professionals and researchers do not consider it as a major issue and usually believe that most children will 'grow out of it' naturally. Therefore, in the first part of this article, I will gather main facts about enuresis, discuss different types of enuresis and try to get a better understanding about the etiology and consequences of such a disorder.

The Diagnostic and Statistical Manual for Mental Disorders ${ }^{3}$ uses the term Enuresis for the repeated voiding of urine into bed or clothing, occurring at least twice a week, for at least three consecutive months, in children over five years of age in the absence of congenital or acquired defects of the central nervous system. Nocturnal Enuresis (NE) refers to bedwetting during asleep. Nocturnal Enuresis is classified into two different groups:

- The first, Monosymptomatic NE (MNE), refers to bedwetting occurring without any incontinence during the day or urological symptoms. ${ }^{4}$ It

1 E.T. Higgins, Self Discrepancy: A Theory Relating Self and Affect, Psychological Review, 1987, 94, 3, p. 319-314.

2 R.J. Butler, Night wetting in children: Psychological aspects, Journal of Child Psychology and Psychiatry and Allied Disciplines, 1998, 39(4), p. 453-463; J. Collier et al., An investigation of the impact of nocturnal enuresis on children's self-concept, Scandinavian Journal of Urology and Nephrology, 2001, 36(3), p. 204-208.

${ }^{3}$ DSM-IV: American Psychiatric Association, 1995, p. 118-119.

${ }^{4}$ R.J. Butler, P. Holland, The three systems: A conceptual way of understanding nocturnal enuresis, Scandinavian Journal of Urology and Nephrology, 2000, 34(4), p. 270-277 
might be an explanation of a normal void going on at an inappropriate and socially unacceptable time and place. ${ }^{5}$

- In contrast, Non-Monosymptomatic NE is associated with day-time indicators of bladder dysfunction, such as urgency or toileting frequency. ${ }^{6}$

In addition, Nocturnal Enuresis is classified to Primary Enuresis and Secondary Enuresis. Primary Enuresis is diagnosed when the child never achieved bladder control for longer than six months. Secondary Enuresis is diagnosed when the Enuretic child had a relapse after being toilet trained for more than six months. ${ }^{7}$ While trying to characterize primary and secondary NE, Fergusson ${ }^{8}$ suggested that children with primary nocturnal enuresis may display minor maturational delay while those with secondary nocturnal enuresis likely to be associated with a more psychogenic etiology. Some researchers found that primary enuresis is frequently linked with a family history of bedwetting as secondary enuresis is more associated with social factors. ${ }^{9}$

Nocturnal enuresis is one of the most prevalent of all childhood problems. ${ }^{10}$ It is estimated that there are between five to seven million children in the United States suffering from nocturnal enuresis ${ }^{11}$ and approximately three-quarters of a million enuretic children over seven years suffering in the United Kingdom. ${ }^{12}$ Different epidemiology studies show different figures regarding the distribution of nocturnal enuresis. From one report, the researchers found that approximately $15-22 \%$ of boys and $7-15 \%$ of girls wet the bed at seven years of age, with nearly 3\% wetting more than twice a week. ${ }^{13}$ A survey of children in the United States, reported higher prevalence rates of $33 \%$ at 5 years, $18 \%$ at 8 years, $7 \%$ at 11 years, and $0.7 \%$ at 17

${ }^{5}$ J.D. Van Gool et al., Subtypes in monosymptomatic nocturnal enuresis, II., Scandinavian Journal of Urology and Nephrology, 1999, 202, p. 8-11.

${ }^{6}$ C.K. Yeung, H.N. Chiu, F.K. Sit, Bladder dysfunction in children with refractory mono symptomatic primary nocturnal enuresis, Journal of Urology, 1999, 162, p. 1049-1054; C.K. Yeung et al., Reduction in nocturnal functional bladder capacity is a common factor in the pathogenesis of refractory nocturnal enuresis, BJU International, 2002, 90(3), p. 302-307.

7 DSM-IV: American Psychiatric Association, 1995, p. 118-119.

${ }^{8}$ D.M. Fergusson, L.J. Horwood, F.T. Shannon, Secondary enuresis in a birth cohort of New Zealand children, Paediatric and Perinatal Epidemiology, 1990, 4(1), p. 53-63.

${ }^{9}$ D.M. Fergusson, L.J. Horwood, Nocturnal Enuresis and behavioral-problems in adolescence A 15 year longitudinal study, Pediatrics, 1994, 95(2), p. 243-243.

${ }_{10} \mathrm{~T}$. Nevéus et al., Depth of sleep and sleep habits among enuretic and incontinent children, Acta Paediatrica, 1999, 88, p. 748-752.

${ }^{11} \mathrm{~K}$. Miller, Concomitant nonpharmacologic therapy in the treatment of primary nocturnal enuresis, Special Edition: Treatment of childhood enuresis. Clinical Pediatrics, 1993, July, p. 32-37.

12 R.J. Butler, Nocturnal enuresis: The child 's experience, Oxford 1994.

13 R.J. Butler, J. Golding, K. Northstone, Nocturnal enuresis at 7.5 years old: Prevalence and analysis of clinical signs, BJU International, 2005, 96, p. 404-410. 
years. ${ }^{14}$ Other research show reduced rates of enuresis; Weintraub and her colleagues use data showing that at the age of 5 years, just $3-7 \%$ are experiencing enuresis and this reduces significantly as age progress ${ }^{15}$.

The etiology of enuresis is well-researched. There is more than one etiology and usually the etiology would be influenced from the discipline the researcher comes from. One of the preferential models, suggest that nocturnal enuresis is Genetic. ${ }^{16}$ Jarvelin et al. ${ }^{17}$, showed that enuresis runs in families, with a reported risk of the order of $77 \%$ where both parents themselves were enuretic. Psychosocially factors can also cause nocturnal enuresis. Disrupting experiences for the child in the early years appear to enhance the exposure to nocturnal enuresis. Traumatic events, that the child is exposed to, such as parents separation or divorce ${ }^{18}$ during a sensitive phase in the development of bladder control (around the age two to three years), have been found to be correlated to the later development of nocturnal enuresis. This has been referred to as the "interrupted learning theory." 19 Other contributing factors that can cause nocturnal enuresis are inferior living conditions, emotional issues, separation from siblings, and adaptation to new family structures and possibly step-parents. ${ }^{20}$ From the physiological aspect, nocturnal enuresis is sometimes explained as bladder instability, a lack of arginine vasopressin release, inability to awake from sleep to a full bladder or to a combination of the three. ${ }^{21}$ Deep sleep is one of the characteristics that are subjectively reported by enuretic children's parents that find it almost impossible to wake their child up. ${ }^{22}$

By now, we understand that Nocturnal Enuresis, is a very common and distressing disorder among children. In the further part of the article I will

\footnotetext{
14 R.S. Byrd et al., Bed-wetting in US children: epidemiology and related behaviour problems, Pediatrics, 1996, 98, p. 414-419.

15 Y. Weintraub et al., Enuresis - an unattended comorbidity of childhood obesity, International Journal of Obesity, 2013, 37(1), p. 75-8.

${ }_{16}$ H. Bakwin, Enuresis in twins, American Journal of Disease in Childhood, 1971, 121, p. 222-225.

17 M.R. Jarvelin et al., Enuresis in seven year old children, Acta Paediatrica Scandinavica, 1988, 77, p. 148-153.

18 M.R. Jarvelin et al., Aetiological and precipitating factors for childhood enuresis, Acta Paediatrica Scandinavica, 1991, 80, p. 361-369.

${ }_{19}$ R.J. Butler, Night wetting in children: Psychological aspects, Journal of Child Psychology and Psychiatry and Allied Disciplines, 1998, 39(4), p. 453-463.

20 A.C. Houts, Nocturnal enuresis as a biobehavioural problem, Behavior Therapy, 1991, 22, p. 133-151.

${ }^{21}$ T. Nevéus, Nocturnal enuresis-theoretic background and practical guidelines, Pediatric Nephrology, 2011, 26(8), p. 1207-1214.

${ }^{22} \mathrm{~T}$. Nevéus et al., Depth of sleep and sleep habits.
} 
focus on one of the many effects of Nocturnal Enuresis - The social and emotional functioning of bedwetters.

\section{The relationship between Social and Emotional functioning and Nocturnal Enuresis}

The relationship between Nocturnal Enuresis and social and emotional functioning has been studied for several decades. In some of the studies, enuretic children found to be in the normal range, having no emotional, social or behavioral problems. ${ }^{23}$ Four decades ago, Baker ${ }^{24}$ found no difference in psychological impact, between children with nocturnal enuresis and matched non enuretic controls. One decade later, a few researchers found that children with nocturnal enuresis appear emotionally normal as a group, falling within the normal range on self-report measures of social and emotional adjustment. ${ }^{25}$ On the anxiety scale, it was found that children with nocturnal enuresis were within the normal range. ${ }^{26}$

In other studies, enuretic children were found to be with significant increase in psychological difficulties compared with their non-enuretic peers. ${ }^{27}$ Some of the later studies, also found that psychological problems among children who wet the bed do not differ significantly from non Enuretic children. ${ }^{28}$ As shown, there are a few researchers that have claimed through the years, that nocturnal enuresis has no effect on social and emotional functioning but they are minority.

However, there is a growing literature investigating whether enuretic children experience more psychological issues compared with non enuretic

23 B.L. Baker, Symptom treatment and symptom substitution in enuresis, Journal Abnorm Psychology, 1969, 74, p. 42-9; S. Wille, I. Anveden, Social and behavioural perspectives in enuretics, former enuretics and non-enuretic controls, Acta Paediatrica, 1995, 84, p. 37-40.

24 B.L. Baker, Symptom treatment.

$25 \mathrm{~W}$. Wagner et al., A controlled comparison of two treatments for nocturnal enuresis, Journal of Paediatrics, 1982, 101, p. 302-307; M.E. Moffatt, C. Kato, I.B. Pless, Improvements in self-concept after treatment of nocturnal enuresis: randomized controlled trial, Journal of Pediatrics, 1987, 110(4), p. 647-652.

26 W. Wagner et al., A controlled comparison.

27 R.J. Butler, Combination therapy for nocturnal enuresis, Scandinavian Journal of Urology and Nephrology, 2001, 35(5), p. 364-369; C. Joinson et al., Psychological problems in children with bedwetting and combined (day and night) wetting: A UK population-based study, Journal of Pediatric Psychology, 2007, 32(5), p. 605-616.

28 J.C. Robinson et al., Self-construing in children with primary mono-symptomatic nocturnal enuresis: An investigation of three measures, Scandinavian Journal of Urology and Nephrology, 2003, 37, p. 124-128. 
children. Numbers of studies have found evidence for increased levels of psychological and social problems among enuretic children compared to non enuretics, with more internalizing and externalizing problems. ${ }^{29}$

Qualitatively based investigations have shown that Nocturnal Enuresis can prove a stressful and confusing problem for children, with social withdrawal, guilt, a sense of difference from others and defenselessness to victimization. ${ }^{30}$ In his research, Butler and his colleagues ${ }^{31}$ investigated fifty five children in an open-ended investigation trying to explore their perception of being a bed wetter. The most frequently expressed psychological implication concerned the social ramifications. Typical experiences of the enuretic child included being teased, feeling unable to share his bedwetting issue to anyone, cannot have friends to sleep over, or stay for the night at a friend's house, avoiding trips which involve an overnight stay and being uneasy with siblings who make threats to tell their friends about the Bedwetting issue. Overall the outcome of having nocturnal enuresis appeared to be a sense of social difference and isolation. Frequent bedwetting may cause difficulties in the relationship between parents and their children, with the child losing confidence, having difficulty in making or keeping friends, and underachieving at school. ${ }^{32}$

Bedwetting without doubt disrupts the child's everyday activity. They complain about having to shower or bath every morning, feel cold on waking, have a bedroom which tends to have an unpleasant odor, make sure they keep friends out of their room, have to change their own bed, and sometimes believe they should avoid going to sleep. ${ }^{33}$

From his large British group of more than 8000 children at 9 years of age, 20 years later Butler ${ }^{34}$ found that there are clear indications that bedwetting is perceived from the child's perspective as a serious and upsetting event to deal with. Bedwetting was found to be the eighth most highly endorsed difficulty, being rated only below a few problematic social events and educational issues. Bedwetting was seen as more difficult than physical sickness, psychological distress, antisocial behavior or displeasure with outward show. In another research, it was found that enuretic children consider bed-

${ }^{29}$ C. Joinson et al., Psychological problems.

30 R.J. Butler, Nocturnal enuresis.

31 R.J. Butler, E.J. Redfern, W. Forsythe, The child's construing of nocturnal enuresis and the prediction of effectiveness using pretreatment variables, Journal of Child Psychology and Psychiatry, 1990, 31, p. 447.

32 T. Wolańczyk et al., Attitudes of enuretic children towards their illness, Acta Paediatrica, 2002, 91(7), p. 844-848.

33 R.J. Butler, Combination therapy.

${ }^{34}$ C. Joinson et al., Psychological problems. 
wetting the third most distressing life event after divorce and parental fights as non-enuretic controls showed much less importance to bedwetting, by considering it less severe than an event such as wearing glasses. ${ }^{35}$

Fergusson $^{36}$ suggested that enuretic children may have an increased risk for psychiatric symptoms. He also suggests in his study, that the association between enuresis and anxiety may continue until the age of fifteen.

Enuretic children and their families could be in an increased risk for psychosocial problems. Enuresis might be a stressor for the whole family. ${ }^{37}$ Social factors related with enuresis such as not meeting the expectations of parents could lead the enuretic child to experience a feeling of failure, resulting in lower self-esteem. ${ }^{38}$

Butler $^{39}$ defines the structure of self as a multidimensional and hierarchal. The individual describes the self through verbalized self-representations across a number of domains such as appearance, social behavior and sporting competence. Self-image can be considered to be a descriptive aspect of self (how a child thinks about him or herself), that is the characteristics, attributes and qualities by which the self is identified. Self-esteem however, indicates an evaluative aspect (how a child feels about him or herself) where individuals judge themselves along dimensions considered by that person to be important. 40 One of the difficulties with research on self-concept has been the obscure description and interchangeability of terminology, leading both to concepts such as self-image and self-esteem being used synonymously. ${ }^{41}$

There is a belief that children with nocturnal enuresis experience a loss of self-esteem ${ }^{42}$. They suffer from low self-esteem as long as they continue to wet their beds. Self-esteem is an important psychological variable given the relationship between low self-esteem and later mental health problems. In their research, J. Collier and his colleagues ${ }^{43}$ revealed a few interesting findings regarding the impact of nocturnal enuresis on children's self-concept. He found that as the frequency of bedwetting gets higher, the greater nega-

${ }^{35}$ N.M. Van Tijen, A.P. Messer, Z. Namdar, Percieved stress of nocturnal enuresis in childhood, British Journal of Urology, 1998, 81 Suppl 3(6), p. 98-99.

36 D.M. Fergusson, L.J. Horwood, Nocturnal Enuresis and behavioral-problems in adolescenceA 15 year longitudinal study, Pediatrics, 1994, 95(2), p. 243-243.

${ }^{37}$ N.M. Van Tijen, A.P. Messer, Z. Namdar, Percieved stress.

38 T. Wolańczyk et al., Attitudes of enuretic children.

39 R.J. Butler, Combination therapy.

${ }^{40} \mathrm{~J}$. Collier et al., An investigation.

41 R.J. Butler, Combination therapy.

42 B. Hägglöf, O. Andrén, E. Bergström et al., Self-esteem before and after treatment in children with nocturnal enuresis and urinary incontinence, Scandinavian Journal of Urology and Nephrology, 1997, 183, p. 79-82.

${ }^{43} \mathrm{~J}$. Collier et al., An investigation. 
tive view of self is perhaps expected. Regarding the gender, he found that girls with nocturnal enuresis usually had a more positive self-image than boys about themselves. Amongst enuretic children, the most vulnerable in terms of self-image were male and those with primary enuresis and also the children that had suffered from high frequency enuresis. It was also found, that if enuresis continues into later ages, these children are likely to become increasingly sensitive to the social ramifications of the problem.

Children that suffer from nocturnal enuresis can experience loss of selfesteem, humiliation and social isolation. All of these experiences can increase the risk for emotional and behavioral problems. ${ }^{44}$

We have discussed here the impacts of Nocturnal Enuresis in general on social and emotional functioning. Let us try and distinguish between two types of Nocturnal Enuresis.

Shaffer 45 claims that secondary enuresis is associated with a series of psychosocial factors, specifically family stresses and these or similar factors are known to be associated with increased risk of behavioral problems in adolescence.

A longitudinal study in New Zealand, showed that enuretic children with secondary enuresis, had higher rates of psychiatric symptoms and behavioral problems at ages eleven and thirteen but these findings were not significant at the age of fifteen. ${ }^{46}$ Other studies did not find significant findings that relates secondary enuresis to behavior problems. ${ }^{47}$ No differences were found in behavioral problems between children suffering from primary nocturnal enuresis to those suffering from secondary nocturnal enuresis. ${ }^{48}$ Nevertheless, it may be that enuretic children with secondary nature, will experience more dryness and therefore develop a more positive selfimage compared to children with primary nature. ${ }^{49}$

Most studies mentioned here, have related to enuretic children. Even though there is a lack of research on this subject, from my clinical experi-

44 S. Wille, Nocturnal enuresis: sleep disturbance and behavioral patterns, Acta Paediatrica, 1994, 83, p. 772-774.

${ }^{45}$ D. Shaffer, Enuresis, [in:] Child and Adolescent Psychiatry: Modern Approaches, eds. M. Rutter, L. Herso, London 1985, p. 465-481.

${ }^{46} \mathrm{M}$. Feehan et al., A 6 yr follow up of childhood enuresis: prevalence in adolescence and consequences for mental health, Journal Pediatry Health Care, 1990, 26, p. 75-79.

47 D. Shaffer, A. Gardner, B. Hedge, Behaviour and bladder disturbance in enuretic children: A rational classification of a common disorder, Developmental Medicine and Child Neurology, 1984, 26, p. 781-792.

48 D.M. Fergusson, L.J. Horwood, Nocturnal Enuresis and behavioral-problems in adolescenceA 15 year longitudinal study, Pediatrics, 1994, 95(2), p. 243-243.

${ }^{49}$ C. Joinson et al., Psychological problems. 
ence, I assume that impacts of Nocturnal Enuresis on young adolescents would be much more severe compared to enuretic children.

\section{Young adolescence with Enuresis}

As stressed earlier, some children suffering from enuresis could be affected negatively by that and some could not.

As some of the researches indicated, during his childhood, the enuretic child might not consider his bedwetting as an issue and might not experience more psychological difficulties compared to his non-enuretic peers. ${ }^{50}$

Butler $^{51}$ (2001), reported that many children who attend clinic give an impression of an outward indifference to their bedwetting. These enuretic children try to reflect themselves as normal persons. Wille ${ }^{52}$, claims that in general children with nocturnal enuresis refer to themselves equally to nonbedwetting children. They display similar social and behavioral traits as their peers. However, for children with constant bedwetting, it is a real issue. Some of the enuretic children will try to deny the problem in the same way they may seek to prevent their 'secret' revealed outside of the clinic. Other enuretic children, specifically those which are suffering for years from the problem, underestimate the impact of the bedwetting in order to protect themselves from the possible disappointment of another failed treatment. ${ }^{53}$

One might assume that as age progress, bedwetting becomes a major issue, and contrary to enuretic children, enuretic adolescents might be exposed to negative social and emotional issues.

For adolescence, nocturnal enuresis becomes an embarrassing and perplexing experience with feelings of guilt and shame, avoidance of social activities, a sense of difference from others, victimization and a loss of selfesteem. ${ }^{54}$

Enuretic children who do not control there bladder before the age of ten years show significant increases in conduct problems, anxiety/withdrawal and attention deficit behaviors. ${ }^{55}$ The risk for these adolescents is highest in

50 B.L. Baker, Symptom treatment; W. Wagner et al., A controlled comparison; M.E. Moffatt, C. Kato, I.B. Pless, Improvements in self-concept after treatment; J.C. Robinson et al., Self-construing in children.

51 R.J. Butler, Nocturnal enuresis.

52 S. Wille, Nocturnal enuresis.

53 R.J. Butler, Nocturnal enuresis.

54 Ibidem.

${ }^{55}$ D.M. Fergusson, L.J. Horwood, Nocturnal Enuresis. 
children who wet their beds every night ${ }^{56}$, and are more likely to be at risk of suicidal behavior. ${ }^{57}$ One of the explanations for all these issues can be explained by Collier and his colleagues who suggested that as children get older, they tend to judge their own image in a more conservative way. ${ }^{58}$

Feehan et al.59 claim that children who were diagnosed with secondary nocturnal enuresis could be at high risk for psychiatric symptoms during young adolescence.

As the enuretic child ages, he tends to show hesitation going to sleepovers, feels that his bedwetting issue is an awful experience that has significant negative influence on his life. ${ }^{60}$

In his Study, Butler ${ }^{61}$ found that enuretic children, even at a young age, interpreted bedwetting as a social phenomenon. Children use to interpret bedwetting more as a social problem, rather than as a health problem. As they mature, bedwetting begins to carry social implications. Therefore, when adolescence with enuresis were asked about the implications of their problem, the lack of ability to take part in social activities with their peers, such as an overnight at a friend's house, were ranked to be the most annoying. Butler suggests that even children at the age of nine years, are well aware to the social difficulties involved when suffering from bedwetting.

Enuresis is not a typical issue among young adolescence. Even though some researchers consider bedwetting to have a significant negative impact on the child's social and emotional functioning. ${ }^{62}$

Some research results show that the enuretic child could develop a normal life during childhood.63 From the authors clinical experience, the enuretic child is still at an age that he is not invited yet to sleep overs, in some cases the parents don't reflect any negative feelings about his bedwetting incidents. Hence, the enuretic child can develop normal social life and probably he will not experience any emotional issues due to his bedwetting issue. Since the bedwetting issue is invisible, there is a possibility that he will not feel different compared to his peers. As age progress, the young adolescence will start to feel that something is wrong with him. He realizes that he

56 T. Nevéus, Nocturnal enuresis-theoretic background.

57 X. Liu, Z. Sun in: T.M. Hyde et al., Enuresis as a premorbid developmental marker of schizophrenia, Brain, 2008, 131, 9, p. 2489-2498.

$58 \mathrm{~J}$. Collier, et al., An investigation.

${ }^{59} \mathrm{M}$. Feehan et al., A 6 yr follow up of childhood enuresis.

${ }^{60}$ C.K. Yeung et al., Reduction in nocturnal functional bladder capacity.

${ }^{61}$ C. Joinson et al., Psychological problems.

62 Ibidem.

${ }^{63}$ R.J. Butler, Nocturnal enuresis. 
can't accept invitations to sleep overs at friend's houses ${ }^{64}$, could be insulted by younger siblings that are already dry or get a negative approach from his parents. The youngster understands that he is different than his peers and this insight could lead to a major gap between the child's current social status to how he relates to his self.

In other words, there could be a gap between the child's beliefs about himself (the way he sees himself) to the way he want to ideally be. This gap might lead to emotional issues and later on affect the social status as well. The author relates to this gap as the "Enuresis emotional and social gap model" (See fig. 1).

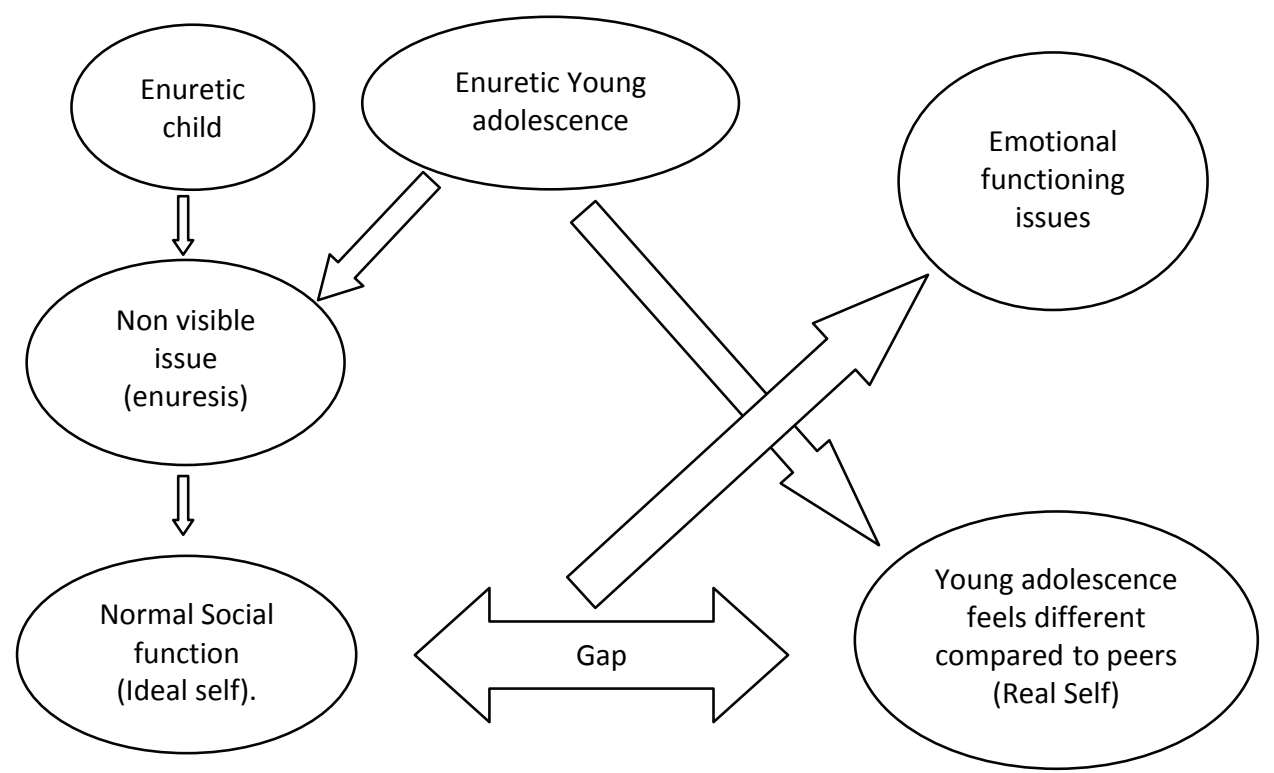

Fig. 1. Enuresis emotional and social gap model

The best way in my opinion to illustrate the burden of nocturnal enuresis during young adolescence and to stress this gap, is to use the following story quoted from a teenager's testimonial shared on a blog:

"...When I was a young kid, I really didn't see that it was anything out of the ordinary I suppose I just assumed that everyone wet the bed...". This statement shows that during childhood, enuresis could be seen as a natural thing having no negative effect on the child.

${ }^{64}$ C.K. Yeung et al., Reduction in nocturnal functional bladder capacity. 
"...but obviously as I got older I realized that wasn't the case and for a while I was very angry about still wetting the bed...but I became very worried that somehow all my friends would know, even though there was no way they could find out. By the time I started at high school I was getting feeling very low about it all - I was convinced that I was the only teenager in the world still wetting the bed...Dealing with a wet bed is no fun, and I had many disrupted nights...". In this part of the testimonial we could see the different approach after turning into adulthood. The enuretic adolescent feels that he is different from his peer group and starts having concerns about the possibility that someone would find out about his problem.

"...It was especially worse on school nights of course...One of the biggest issues is the stigma surrounding bedwetting, which doesn't exist with other conditions... However I would never even consider talking about bedwetting, and up until very recently only people within my family knew. Getting rid of this sort of stigma would be such a huge improvement - if it was easier to talk about it and know that people wouldn't make any sort of fuss then I wouldn't have missed out on so many things, sleepovers, school trips etc." Connor, 16 yo (ericuk.wordpress.com, 2013)

The last part of the testimonial emphasis the enormous social and emotional issue enuresis is causing the adolescent. There seems to be a gap between his beliefs about himself during his childhood, which might help him to develop a normal social life, to his feeling of difference while turning into adolescence.

In order to explain this assumption, the author choose to use the "Self discrepancy theory". .5

\section{Social and Emotional functioning of adolescents in perspective of Self-Discrepancy Theory (SDT)}

Self-discrepancy theory (SDT) ${ }^{66}$ is based on gaps or inconsistencies in a person's life. SDT has a few purposes:

1. Differentiate between different distresses certain people experience.

2. Find a correlation between different discrepancies to different psychological states.

3. Try understanding in a better way the discomfort one may feel while experiencing a specific discrepancy.

SDT suggests two cognitive dimensions: "domains of the self and standpoints on the self". Domains of the self: 1 . The actual self - reflects the beliefs of yourself or someone else about the attributes you possess. 2. The

\footnotetext{
${ }^{65}$ E.T. Higgins, Self Discrepancy.

66 Ibidem.
} 
ideal self - reflect the beliefs of yourself or someone about what you should ideally be (what I wish to be). 3. The ought self - reflects the beliefs of yourself or someone about what you should actually do (the obligation that I should take).

One of the classical examples for the difference between the ideal self and the ought self has to do with the "women's role" in the world. Many women wish to have a successful career (the ideal self) as other individuals will believe that they should be a "stay at home mother" (ought self). ${ }^{67}$

Standpoints of the self: in order to differentiate between different domains of the self, it's important to check the perspective involved or in other words - who is the person that is holding beliefs about myself? There are two options: a. my "personal standpoint" or b. standpoint of a "significant other" (family, peer). For instance, there could be a gap between what I believe I should be to what a significant other would believe I should be.

SDT theory tries to explain how different discrepancies cause different emotional distress. Higgins considers two main discrepancies:

Actual: Ideal (A:I) discrepancy - there is an inconsistence between one's actual beliefs about himself to what he thinks he should possess. Higgins claims that Actual: Ideal (A-I) discrepancies refer to one's difficulty of achieving personal goals and wishes. He assumes that A-I discrepancies would be related to feelings of sadness, depression and disappointment. Actual:Ought $(\mathrm{A}: \mathrm{O})$ - there is an inconsistence between one's actual beliefs about himself to what he thinks he is obligated to be. Actual: Ought (A-O) discrepancies refer to the conflict between ones' feeling that he can't fulfill his obligations. He assumes that A-O discrepancies would be related to feelings of anxiety and fear.

SDT theory might be useful to explain what an enuretic adolescent is experiencing.

I assume that the young adolescent with enuresis is experiencing two major discrepancies: the first one would be the Actual: Ideal discrepancy; the youngster feels that there is a gap between his current bedwetting issue to his will to be dry. He might feel disappointed and depressed from the fact that he is not capable of controlling his own body.

The second discrepancy would be the Actual:Ought discrepancy; on specific occasions when the youngster is invited to sleep overs with peers, he might be terrified from the possibility that his secret might be revealed. There would be in this cases a major gap between his current bedwetting issue to what society (in this case the peer group) might think of him in case he would have an incident. This might result in anxiety and fear.

${ }^{67}$ Ibidem. 
Heron \& Smyth 68 (2013) try to connect different situations that one could experience to different types of emotional states. They defined two main situations: 1. Absence of positive results (actual or expected), which is linked with depression related emotions (e.g., unhappiness, displeasure); and 2. Attendance of negative results (actual or expected), which is linked with anxiety related emotions (e.g., horror, danger, tenseness). Heron and Smith show by using data from six decades ago, that psychological states are a function of the combination between the nature of external events and individual's interpretations of those events. They also explain this point by using more updated studies that there could be different interpretations to the same event by different people.

Both discrepancies might yield major emotional issues. The youngster on one hand could have a successful social life that till this point was not threatened. As Butler ${ }^{69}$ found in his research, as a child, the enuretic could feel and reflect indifference compared to his peers. At the transition phase to young adolescent (approximately at the age of 10) the youngster would feel that his social status might be fragile. He starts to realize at this stage that his bedwetting issue might cause loss of friendships and damage his social status. As Yeung indicates, the youngster will have major negative social and emotional implications caused by his bedwetting issue ${ }^{70}$. In order to deal with it, the youngster will do everything to avoid sleep overs. This might lower the levels of anxiety but amplify the Actual: Ideal discrepancy. In other words, dealing with different strategies to reduce the A:O discrepancy might yield in increasing the A:I discrepancy.

Another important factor that could have a major influence on these discrepancies would be parents approach to the bedwetting issue. It is important to distinguish between the parents role to the peers role. Unlike the peers, parents are aware of the problem. In many cases, they try to help their child to deal with it. If the parents would reflect negative approach to their child, I would assume that the A:O discrepancies would be more severe. If the parents would reflect supportive approach, I would assume that it might sublimate the discrepancy. Even in cases where the parents try to offer their help, it might still aggravate the A:O discrepancy since the bedwetter can interpret his parents efforts in helping him as a expecting him to be dry.

${ }^{68} \mathrm{~K}$. Heron et al., Assessing body image in young children: A preliminary study of gender, age, and racial differences, SAGE Open, 2013.

${ }^{69}$ R.J. Butler, Nocturnal enuresis.

${ }^{70}$ C.K. Yeung et al., Reduction in nocturnal functional bladder capacity. 
Sharing my experience from the clinical field, I have seen countless cases in which the young adolescence expressed enormous concern while preparing himself to sleep overs. This is very common before summer camps when a few weeks of sleep overs are a very threatening scenario. In addition, they show hopelessness regarding their issue.

\section{Conclusion}

We can understand by now that enuresis is a stressful disorder that could have major negative implications on the adolescent social and emotional functioning.

The SDT theory explains the gap that could evolve when an enuretic child enters adolescence and still suffers from bedwetting. In my opinion, this gap could explain these social and emotional issues.

The gap that was demonstrated sheds light on the importance of addressing this problem as early as possible. This is the reason it is extremely important to check this gap empirically in a future research.

\section{BIBLIOGRAPHY}

American Psychiatric Association, Diagnostic and statistical manual of mental disorders: DSM IV (4th ed.), American Psychiatry Press, Washington DC 1995.

Baker B.L., Symptom treatment and symptom substitution in enuresis, Journal Abnorm Psychology, 1969, 74.

Bakwin H., Enuresis in twins, American Journal of Disease in Childhood, 1971, 121.

Butler R.J., Nocturnal enuresis: The child 's experience, Butterworth Heineman, Oxford 1994.

Butler R.J., Night wetting in children: Psychological aspects, Journal of Child Psychology and Psychiatry and Allied Disciplines, 1998, 39(4).

Butler R.J., Combination therapy for nocturnal enuresis, Scandinavian Journal of Urology and Nephrology, 2001, 35(5).

Butler R.J., Golding J., Northstone K., Nocturnal enuresis at 7.5 years old: Prevalence and analysis of clinical signs, BJU International, 2005, 96.

Butler R.J., Holland P., The three systems: A conceptual way of understanding nocturnal enuresis, Scandinavian Journal of Urology and Nephrology, 2000, 34(4).

Butler R.J., Redfern E.J., Forsythe W., The child's construing of nocturnal enuresis and the prediction of effectiveness using pretreatment variables, Journal of Child Psychology and Psychiatry, 1990, 31.

Byrd R.S., Weitzman M., Lanphear N.E., Auinger P., Bed-wetting in US children: epidemiology and related behaviour problems, Pediatrics, 1996, 98.

Collier J., et al., An investigation of the impact of nocturnal enuresis on children's self-concept, Scandinavian Journal of Urology and Nephrology, 2001, 36(3). 
Feehan M., McGee R., Stanton W., Silvan S.R., A 6 yr follow up of childhood enuresis: prevalence in adolescence and consequences for mental health, Journal Pediatry Health Care, 1990, 26.

Fergusson D.M., Horwood L.J., Nocturnal Enuresis and behavioral-problems in adolescenceA 15 year longitudinal study, Pediatrics, 1994, 95(2).

Fergusson D.M., Horwood L.J., Shannon F.T., Secondary enuresis in a birth cohort of New Zealand children, Paediatric and Perinatal Epidemiology, 1990, 4(1).

Hägglöf B., Andrén O., Bergström E. et al., Self-esteem before and after treatment in children with nocturnal enuresis and urinary incontinence, Scandinavian Journal of Urology and Nephrology, 1997, 183.

Heron K., Smyth J., Akano E., Wonderlich S., Assessing body image in young children: A preliminary study of gender, age, and racial differences, SAGE Open, 2013.

Higgins E.T., Self Discrepancy: A Theory Relating Self and Affect, Psychological Review, $1987,94,3$.

Houts A.C., Nocturnal enuresis as a biobehavioural problem, Behavior Therapy, 1991, 22.

Hyde T.M., Deep-Soboslay A., Iglesias B., Callicott J.H., Gold J.M., Meyer-Lindenberg A., Honea R.A., Bigelow L.B., Egan M.F., Emsellem E.M., Weinberger D.R., Enuresis as a premorbid developmental marker of schizophrenia, Brain, 2008, 131, 9.

Jarvelin M.R., Vikevainen-Tervonen L., Moilanen I., Huttunen N.P., Enuresis in seven year old children, Acta Paediatrica Scandinavica, 1988, 77.

Jarvelin M.R., Moilanen I., Kangas P., Moring K., Vikevainen-Tervonen L., Huttunen N.P., Seppanen J., Aetiological and precipitating factors for childhood enuresis, Acta Paediatrica Scandinavica, 1991, 80.

Joinson C., Heron J., Edmond A., Butler R., Psychological problems in children with bedwetting and combined (day and night) wetting: A UK population-based study, Journal of Pediatric Psychology, 2007, 32(5).

Miller K., Concomitant nonpharmacologic therapy in the treatment of primary nocturnal enuresis, Special Edition: Treatment of childhood enuresis. Clinical Pediatrics, 1993, July.

Moffatt M.E., Kato C., Pless I.B., Improvements in self-concept after treatment of nocturnal enuresis: randomized controlled trial, Journal of Pediatrics, 1987, 110(4).

Nevéus T., Nocturnal enuresis-theoretic background and practical guidelines, Pediatric Nephrology, 2011, 26(8).

Nevéus T., Hetta J., Cnattingius S., Tuvemo T., Läckgren G., Olsson U., Stenberg A., Depth of sleep and sleep habits among enuretic and incontinent children, Acta Paediatrica, 1999, 88.

Robinson J.C., Butler R.J., Holland P., Doherty-Williams D., Self-construing in children with primary mono-symptomatic nocturnal enuresis: An investigation of three measures, Scandinavian Journal of Urology and Nephrology, 2003, 37.

Shaffer D., Enuresis, [in:] Child and Adolescent Psychiatry: Modern Approaches, eds. M. Rutter, L. Herso, Blackwell Scientific Publications, London 1985.

Shaffer D., Gardner A., Hedge B., Behaviour and bladder disturbance in enuretic children: A rational classification of a common disorder, Developmental Medicine and Child Neurology, 1984, 26.

Van Gool J.D., Nieuwenhuis E., ten Doeschate I.O., Messer T.P., de Jong T.P., Subtypes in monosymptomatic nocturnal enuresis, II., Scandinavian Journal of Urology and Nephrology, 1999, 202.

Van Tijen N.M., Messer A.P., Namdar Z., Percieved stress of nocturnal enuresis in childhood, British Journal of Urology, 1998, 81 Suppl 3(6). 
Wagner W., Johnson S., Walker D., Earther R., Wittner J., A controlled comparison of two treatments for nocturnal enuresis, Journal of Paediatrics, 1982, 101.

Weintraub Y., Singer S., Alexander D., Hacham S., Menuchin G., Lubetzky R., Steinberg D.M., Pinhas-Hamiel O., Enuresis - an unattended comorbidity of childhood obesity, International Journal of Obesity, 2013, 37(1).

Wille S., Nocturnal enuresis: sleep disturbance and behavioral patterns, Acta Paediatrica, 1994, 83.

Wille S., Anveden I., Social and behavioural perspectives in enuretics, former enuretics and nonenuretic controls, Acta Paediatrica, 1995, 84.

Wolańczyk T., Banasikowska I., Złotkowski P., Wiśniewski A., Paruszkiewicz G., Attitudes of enuretic children towards their illness, Acta Paediatrica, 2002, 91(7).

Yeung C.K., Chiu H.N., Sit F.K., Bladder dysfunction in children with refractory mono symptomatic primary nocturnal enuresis, Journal of Urology, 1999, 162.

Yeung C.K., Sit F.K.Y., To L.K.C., Chiu H.N., Sihoe J.D.Y., Lee E., Wong C., Reduction in nocturnal functional bladder capacity is a common factor in the pathogenesis of refractory nocturnal enuresis, BJU International, 2002, 90(3). 